\title{
Experienced EFL teachers' beliefs about feedback on student oral presentations
}

\author{
Bo Wang ${ }^{1 *}$, Shulin $\mathrm{Yu}^{2}$ and Timothy Teo ${ }^{3}$
}

\author{
* Correspondence: \\ yb57101@umac.mo \\ ${ }^{1}$ Faculty of Education, University of \\ Macau, Room 2042, E33, Av. da \\ Universidade, Taipa, Macau, China \\ Full list of author information is \\ available at the end of the article
}

\begin{abstract}
Although a number of studies have examined EFL teachers' beliefs of feedback on student writing, few have investigated teachers' feedback beliefs about student oral activities like oral presentations. To fill this research gap, this study explores three experienced EFL teachers' beliefs about feedback on oral presentations in terms of the nature, focus, interpersonal functions, strategies and source of teacher feedback. Using semi-structured interviews and classroom observations, this study identified six major beliefs about feedback on student oral presentations and provided implications regarding how EFL teachers provide effective feedback to enhance student performance in oral presentations.
\end{abstract}

Keywords: Teacher belief, Teacher feedback, Oral presentations, English as a foreign language

\section{Introduction}

Teacher feedback is viewed as a critical component of classroom-based instruction in second language education. Over the past few decades, there has been a substantial amount of research on teacher feedback conducted in various contexts like English immersion classrooms, adult English as a second language (ESL) classrooms, English as a foreign language (EFL) secondary schools, etc. (see Lyster, Saito and Sato 2013, for review). Much has been written about oral and written corrective feedback (CF) in the acquisition of linguistic knowledge and in the instruction of second language (L2) writing (e.g. Hyland and Hyland 2006; Sheen 2010). These studies have shown that teacher feedback is effective in facilitating students' linguistic development (particularly grammatical accuracy) and enhancing students' text revisions. Some earlier feedback studies concern with the description of how L2 teachers give feedback, and what options are available to them while correcting students' errors (e.g. Chaudron 1986; Fanselow 1977). This domain has expanded since the 1990s when there is a proliferation of research interest into the relationships between teacher beliefs and classroom behaviours (Borg 2006). Following this line of inquiry, recent feedback studies examine what beliefs teachers hold when they correct errors in students' L2 writing and oral production, as well as how these teacher beliefs are put to CF practices (e.g. Junqueria and Kim 2013; Lee 2009). Nevertheless, the findings of these studies may not be directly to language teachers who offer feedback on task-based oral activities like oral presentations.

(c) The Author(s). 2018 Open Access This article is distributed under the terms of the Creative Commons Attribution 4.0 International License (http://creativecommons.org/licenses/by/4.0/), which permits unrestricted use, distribution, and reproduction in any medium, provided you give appropriate credit to the original author(s) and the source, provide a link to the Creative Commons license, and indicate if changes were made. 
As a highly routinized classroom activity for university students, oral presentation has been shown to be beneficial to learner development of L2 and related personal skills (Girard, Pinar and Trapp 2011; King 2002). Oral presentations are essentially student-centred language tasks. In most cases, when students are asked to make oral presentations in class, they can choose and decide on what they want to address in their presentations as well as how they will present their topics to the audience (e.g. peers and teachers). Consider the group presentation as an example. Students are often engaged in a process-oriented learning in which they work together to prepare for their oral presentations. In some classroom settings, oral presentations also involve follow-up phases where presenting students are asked to answer unanticipated questions. Both these planned and unplanned language output is potentially helpful for students to develop proficiency in English (Bunch 2009).

Another benefit of oral presentations is that students can use four English skills (i.e. listening, speaking, reading and writing) in an integrated way (Brooks and Wilson 2014; King 2002). More often the spoken components of oral presentations are recognized because students are required to speak while presenting. Meanwhile, the communicative nature of oral presentations allows non-presenting students as the audience to practice listening skills in such a way that they are able to interact with the presenters. When preparing for oral presentations, students need to conduct extensive English readings to find out supporting materials for the presenting topics; and then write out appropriate information in their PowerPoint slides. In a nutshell, the use of oral presentations helps bridge "the gap between language study and language use" (King 2002, p. 402). Oral presentations have far more advantages than simply promoting English proficiency. Oral presentations serve as effective means of teaching lifelong skills that can extend beyond the educational setting into a professional context after graduation since many future employers attached great importance to communication skills and the ability to give formal presentations (Pittinger et al. 2004).

\section{Theoretical framework}

Teacher beliefs are generally regarded as the views and ideas that teachers hold about the task of L2 and FL language learning (Borg 2006). The study reported here is based on the theoretical framework of teacher beliefs as socially constructed meaning-making activity (Negueruela-Azarola, 2011). As Vygotsky's (1978) sociocultural theory (SCT) foregrounds the importance of mediation through cultural tools (such as language and concepts) in second language acquisition (SLA), beliefs are not only social in origin but also "dynamically and personally transformed in the process of internalization" (Negueruela-Azarola 2011, p. 360). In other words, teacher beliefs are social yet personally meaningful. Within this SCT approach, SLA beliefs are recognized as embedded in the participants' contexts and related to their experiences (Barcelos 2003). Contexts, understood as teachers' constructions of their experiences, are therefore significant to interpretations of teacher beliefs.

Studies following the SCT tradition are carried out on language teachers' beliefs about giving feedback and how the teachers' beliefs influence their feedback practices. For example, the two EFL teachers in Mori's (2011) case study in Japan held teaching beliefs of developing university-level students' self-confidence, independence, and oral 
communicative abilities. Consequently, their oral CF practices were characterized by implicitness; that is, the two EFL teachers did not attempt to make overt correction of language errors. Some studies have highlighted the impact of contextual constraints like limited time, exam pressure and instructional requirements in teacher practices of providing feedback (e.g. Lee 2009; Lee, Leong and Song 2017). Besides, research has also shown that classroom experiences play a role in constructing language teachers' beliefs, and guide their selection and adjustment of teaching strategies for coping with everyday instructional challenges (Borg 2006). Experienced teachers usually possess "fully developed schemata of teaching" and "expert knowledge" that may not be available to novices (Borg, 2006, p. 47), thus being selected as the research focus of this study for its modelling roles in teacher education.

Given that little is actually known about what EFL teachers think about feedback on this communicative-task of oral presentation, the present case study investigates three experienced EFL teachers' beliefs about giving feedback on student oral presentations. This study can highlight the complex nature of teacher decision making, and offer pedagogical implications for teacher feedback practices in oral presentations.

\section{The study \\ Methodology}

A qualitative case study was adopted to examine three Chinese EFL university teachers' feedback beliefs in the context of student oral presentations. This study was guided by the following research question: What beliefs did the three experienced EFL teachers hold about their feedback on oral presentations? We hope that the insights obtained from this case study will have implications for language teachers in giving feedback to promote students' oral presentations and their oral English.

\section{Participants and context}

Three teachers, Han (male), Wang (female) and Liu (female) (all pseudonyms), who are native speakers of Chinese, were selected to participate in the study through purposive sampling. All three teachers belong to the department of English language and literature in one mainland Chinese university. The teachers all had BA degrees in English. In addition, Wang had a MA degree in English Literature while Han and Liu had MA degrees in Applied Linguistics. Wang had 11 years of teaching experience, Han had 19 years, and Liu had 27 years. They were selected because they were all experienced English teachers and regularly assigned oral presentation tasks to their students in class. In addition, they developed their individual course syllabi and were the head teachers of these courses. Hence, this case-study sample enabled us to obtain a better understanding of experienced EFL teachers' beliefs about teacher feedback on oral presentations.

At the time of the study, Liu taught Communicative English to sophomore English majors and Wang and Han taught the juniors Audio-Visual English and Advanced English, respectively. Their courses were core modules that the English major students at their universities were required to complete before graduation, according to the English Department's programme handbook. Oral presentation was positioned as a fundamental part of the syllabus design and was oriented towards students' development 
of integrated English skills, particularly oral communicative competence. In the above three English courses, students, either individually or in pairs/groups, delivered prepared oral presentations with the aid of PowerPoint slides. This task (including teacher feedback) lasted for about 15 to $25 \mathrm{~min}$. The topics of the oral presentations were usually daily-life based and related to the course contents, such as cross-cultural differences, college class attendance-taking, environment protection, safe on-line shopping, etc. Since many Chinese EFL students lack the opportunities to give oral presentations in high school, the teachers in this study usually introduced students to the specific genre of oral presentations before students work on their tasks. For example, students are instructed on how to use oral language and visual aids in their presentations, as well as how to use eye contact and project voice to ensure successful delivery of presentations. The criteria of effective oral presentations are also shared among the students before their delivery.

\section{Data collection}

Before embarking on this study, the researchers have completed and submitted the application form to the Research Ethics Committee of their affiliated university, and got approved to conduct this study. Data for the study included classroom observations and three rounds of in-depth interviews with the three participants over one semester. All teacher participants were informed of the purpose of this study and took voluntary participation in this study. Also, the teachers gave written consent for the researchers to observe their class and use the interview data. Specifically, the three courses (i.e. Communicative English, Audio-Visual English and Advanced English) were observed; and during the observations, the first researcher took field notes to write down how these three case-study teachers provided feedback to student oral presentations with specific attention paid to the foci of feedback as well as the strategies that teachers employed in feedback processes. The observations along with field notes were mainly used as stimuli for the teacher interviews.

Apart from classroom observations, semi-structured interviews were carried out to investigate the participating teachers' beliefs in relation to their feedback practices. The first round of interviews were conducted before the classroom observations and focused on the teachers' teaching experiences with student oral presentations. The second and the third rounds of interviews were conducted after the classroom observations. In the interviews, the teachers were encouraged to talk about their views and perceptions of their feedback practices, as well as reflect on their experiences of feedback. The interviews were conducted individually with each teacher and audio-recorded with the permission of all of the teacher participants. Each interview lasted one to one and a half hours. The core interview questions were as follows:

(1) What do you think the main role of teacher feedback is in students' oral presentations?

(2) What aspects of oral presentations do you focus on in your feedback? Why?

(3) Can you describe and explain your deployment of feedback strategies in students' oral presentations? 
(4) Do you use any other feedback mechanisms in addition to teacher feedback? Why or why not?

(5) When you give feedback, what forms of feedback do you think to be useful to students to help them improve their oral presentation performance? Why?

(6) If you were to pass one piece of advice about giving effective feedback to a new EFL teacher commenting on students' oral presentations, what would that be?

\section{Data analysis}

The interview data were fully transcribed and analysed qualitatively (Miles and Huberman 1994). The first step of the analysis involved reading through the interview transcripts and identifying five aspects of teacher beliefs about feedback: "nature", "focus", "interpersonal function", "strategies" and "source". Based on this preliminary analysis, we developed a coding scheme (Table 1) by modifying and integrating the conceptual frameworks from (1) Wiliam's (2001) formative and summative assessment; (2) Hyland and Hyland's (2001) feedback functions (i.e. praise, suggestion and criticism); and (3) Brookhart's (2008) feedback strategies (i.e. mode, timing, audience and amount). During the coding process, we looked for patterns for generalisations within each case and among the three cases, and sorted the information into relevant themes based on the identified categories.

\section{Findings and discussion}

In this section, we describe and discuss the three experienced EFL teachers' beliefs about giving feedback to oral presentations, illustrated with excerpts from the interviews. Attempts are also made to explain the rationales underlying the teachers' feedback beliefs.

Table 1 Coding scheme of teacher beliefs

\begin{tabular}{ll}
\hline Feedback & Coding \\
\hline Nature & - Formative: process-oriented, description of strengths/weaknesses \\
& - Summative: product-focused, evaluation of overall performance \\
Focus & - Language skills \\
& - Content and subject knowledge \\
& - Organisation (e.g., structure, signposting, etc.) \\
& - PowerPoint demonstration \\
& - Presence (e.g., body language, eye contact, poise, etc.) \\
& - Praise \\
& - Suggestion \\
- Criticism & \\
- Moderpersonal function & - Timing: immediate, delayed \\
& - Audience: individual, group/whole class \\
Strategies & Amount: comprehensive, selective \\
& - Teacher \\
Source & Peer \\
& - Self \\
\hline
\end{tabular}


Belief 1: Teacher feedback should be process-oriented, descriptive and formative in nature

All three teachers stated in the interviews that their primary reason for providing feedback on student presentation tasks was to improve student learning and task performance. They argued that formative feedback was more effective than summative evaluation, as students received the feedback during on-going learning processes. For example, Wang said, "I think feedback in the form of letter grades are for demonstrating student learning results. They are evaluative and not informative enough. Students do not receive any suggestions for improving both their current and further oral presentation tasks". Liu also expressed the concern that poor grades can damage weak students' self-confidence. She thought that teachers should describe students' learning strengths and weaknesses and make further suggestions when they provide feedback. In terms of assigning grades to students, Han thought that grades accompanied by specific feedback could be used to encourage students' development. He remarked, "Students gain a sense of self-control of their performance because grades can inform their unattained learning goals and motivate them to make more endeavours towards these goals". The findings indicate that the three teachers held different attitudes toward grading as one form of teacher feedback. Grades are commonly viewed as one component of summative assessment, but can simultaneously serve formative purposes if they are used for reinforcement of learning, as believed by Han. This corroborates Wiliam's (2001) observation that what makes formative assessment really different from summative assessment lies in its use of the information gathered from the assessment rather than the time of the assessment. Overall, the three experienced teachers believe that feedback should close a gap between achieved and desired learning goals in the context of oral presentation tasks.

Belief 2: Teacher feedback should focus on the mastery of content knowledge and development of oral communicative and presentation skills.

The interview data suggest that the teachers focus on both the students' oral communicative competence and the contents of their oral presentations. When interviewed, the teachers remarked that they usually did not want to correct grammar mistakes and mispronunciations for fear of interrupting oral fluency. They thought that feedback should focus on promoting students' development of communicative skills. For instance, Liu viewed language as a means of communication and argued that learners should have the ability to use language forms to achieve communicative purposes. She said, "I emphasised that students should use appropriate intonation and voice patterns to reach the expected communication effects when they present". Wang and Han attached great importance to the expression of oral language through proper body language and eye contact, stating that communicative strategies entailed more than speaking clearly. In addition, Han considered well-organised PowerPoint slides as a communicative and presentation strategy; he said, "I think good signposting helps clarify the audience's thought and logic structures of the overall presentation".

Clearly, this particular finding suggests that the three teachers do not perceive oral presentations as opportunities for grammar instruction. Besides, the observational data of field notes showed that the teachers mostly gave feedback on the topics and contents of oral presentations, possibly because, as Liu said, "We think oral presentations are 
one of the ways to improve student learning of course materials". In a nutshell, the above finding suggests that the three EFL teachers are preoccupied with developing students' communicative competence and idea development rather than consolidating linguistic knowledge, which is found to be inconsistent with the majority of research on teacher written feedback practices. For example, when giving feedback to student writing, teachers in Lee's (2009) study have a specific focus on students' non-target-like linguistic structures in their written feedback, with $94.1 \%$ of the written feedback addressing language errors and only $3.8 \%$ and $0.4 \%$ addressing content on organizational issues in student writing.

As for students' language errors, the interview data indicated that the three teachers thought selective CF should be delivered on student oral presentations. For instance, Liu thought that language errors in particular should be selectively corrected. She said, "I think priority can be given to those errors that impact our comprehension like phonological errors". Liu's belief coincided with that of Han who argued that he did not want to fix every mistake, especially every grammatical error in student speech. Han explained that too much error correction may do harm to the teacher-student relationship and student confidence to speak up. This belief of the benefits of selectively attending to spoken errors (also called focused CF in written feedback research) also wins support of many researchers in the field of written feedback. Focused written CF facilitates L2 learners' better understanding of the errors since learners are more likely to notice and attend to the feedback when a limited number of written error types is marked (Bitchener and Ferris 2012, Ellis, Sheen, Murakami and Takashima 2008). Instead, unfocused written CF can result in "information overload" (Bitchener 2008, p. 109) when students process the feedback.

Another reason for the teachers' preference for selective CF was the pressure of limited time. Han and Wang mentioned that the class comprised several activities other than oral presentation. It seems that the teachers do not want to address and correct every mistake that occurs in student presentation performance. The present study confirms findings from previous research concerning why teachers correct spoken errors the way they do. Whether the three participating teachers provided or opted not to provide oral CF depended partly on factors such as instructional focus, time constraints, student emotional well-being, as previous CF studies have shown (e.g. Mori 2011; Rahimi and Zhang 2015; Roothooft 2014). In this study, all three teachers tried to cultivate their students' communicative abilities and confidence in oral expression. Behind this undertaking were the teachers' beliefs about how to communicate with others effectively through oral presentations. These teacher beliefs mediated by the pedagogical focus of language teaching, and teacher-student interpersonal relationships provided a credible reference point for the teachers with which to decide what to focus on and what specific roles to take on when giving feedback.

Belief 3: Praise and constructive criticism help build good rapport with students and create supportive learning environments

In the interview, all three teachers opined that teacher feedback in the form of praise encourages student learning and participation, as it can help students get a sense of achievement. Yet, the teachers perceived teacher praise differently. Wang thought that 
praise should be targeted at individual student's presentation performance; otherwise it runs the risk of shifting students' attention to themselves or their abilities, thus discouraging further learning efforts. Liu and Han emphasised the importance of genuine praise in establishing a healthy teacher-student relationship. For example, Han said, "I think teachers should not praise a great deal. You need to be sincere. What matters is its quality because only genuine praise can convey feedback information". When asked about giving feedback on student weaknesses, the case-teachers perceived constructive criticism (also called suggestions) as one way to mitigate the potential threat of blunt criticism while allowing further learning improvement at the same time. One plausible reason for such mitigation is that the teachers take students' personality traits and emotional well-being into account, and believe that critical feedback can suppress learning opportunities and contribute to negative classroom climates. As Wang explained, "I think Asian students, especially the Chinese, are withdrawn. They lack confidence in self-expression in public. Teachers' comments, if expressed negatively, may inhibit rather than encourage their language learning". This finding seems to echo Forgas and Tehani's (2005) finding that experienced teachers are highly attentive to the effect of mood on their feedback provision. This study demonstrated that all of the feedback given by the three teachers has a positive intention but is not confined to general praise, and the like. Indeed, the teachers' beliefs regarding praise point the need to pay attention to the psychological aspect of teacher praise which can become problematic because low level of praise fails to communicate genuine feedback information to students. Even worse, it runs the risk of shifting students' attentions to themselves and severing the relationship between learning effort and achievement, thus discouraging students' further efforts in response to teacher feedback (Dweck 2007; Skipper and Douglas 2012).

Belief 4: The choice of immediate or delayed feedback should depend on specific aspects of student oral presentations

When interviewed, the teachers generally attached equal importance to both immediate and delayed feedback and thought the difference was related to different aspects pertaining to student presentations. For example, Wang and Liu thought that students' overall presence deserved immediate feedback because it represented the teacher's first impression. In terms of delayed feedback, Han thought that delayed corrections of spoken errors and spelling mistakes on PowerPoint slides was more important, as he said, "Personally, I prefer not to immediately point out the presenting student's oral errors like mispronunciations when they are delivering presentations, because by doing this, the flow of communication will be interrupted. I want the student to express their ideas in a smooth way". The teachers also thought that delayed feedback was more specific and systematic. As argued by Liu, "I may not be familiar with some students' presentation contents, so I think I need to have some time to reflect before I give them specific suggestions". This was further supported by Han, who thought that the logic structures of PowerPoint slides required careful thought on the teacher's part, and thus delayed feedback was more useful. Overall, the teachers hold rather complex beliefs about when to give feedback on student oral presentations. These findings seem to echo King, Young and Behnke's (2000) claim that immediate feedback was effective in 
improving task performance that require automatic processing (e.g. enhancing body language and eye contact), whereas delayed feedback was effective in enhancing aspects of tasks that require deliberative and effortful processing (e.g. revising oral presentations in terms of contents and logic structures).

\section{Belief 5: Teacher feedback should be addressed to both individuals and the whole group/class accordingly}

The data analysis showed that the three teachers held different opinions about the composition of their feedback audience. Liu thought that feedback should be given to individual presenters because it was specific and contained useful and distinctive information related to individuals' learning and development. Similarly, Han expressed the need for individual feedback by considering the students' interests. He said, "Because students' language proficiencies are different and they also have different needs, if I give too much collective feedback, the presenting student may not feel it useful and therefore lose interest". However, Wang thought that feedback should often address the common problems in student performance, as this benefited the whole group or class. She explained that collective feedback can engage non-presenting students' attention; otherwise, these students would not listen attentively and take her feedback seriously. Wang further stated that individual feedback took a large amount of time, which could otherwise be allocated to other classroom activities. Although the teachers held different beliefs in terms of the audience of their feedback, they all appeared to believe that feedback like all communication works best when it conveys the teacher's caring about student learning and performance (Brookhart 2008). Also, this finding highlights that teachers' beliefs are not only mediated by afore-mentioned instructional focus, but also a multitude of learner factors like individual student needs and L2 proficiency, as previous feedback studies have shown (e.g. Mori 2002, 2011).

Belief 6: The incorporation of self-generated and peer feedback develops self-reflection and fosters cooperative language learning

In the interviews, Han and Liu thought peer interaction in the feedback processes was very useful. They thought that peer students should be encouraged to offer specific and public feedback to the presenting students. Liu proposed a "question-answer" time in the teacher-led follow up to elicit peer contributions. She remarked, "I think the class deserves an opportunity to respond to the presenting students' performances. Such interactions benefit both presenters and the audience in helping them to clarify ideas and check understandings". Similarly, Han acknowledged the usefulness of peer feedback in fostering cooperative learning. Encouraging students to give suggestions helped co-construct feedback information and demonstrated non-presenters' interest and care in their peers' performances. In addition to peer feedback, Wang emphasised the importance of self-generated feedback. She said, "This self-led delivery of feedback gives students a sense of ownership. They have the right to evaluate and comment on their own work". Wang's beliefs suggest that language learners should be conscious of and reflect on their own learning processes. The potential role of peer feedback and self-feedback is also recognized by teachers in the EFL writing classrooms (e.g., Lundstrom and Baker 2009; Min 2006). Specifically, students have dual roles to play in 
the feedback process, i.e. - givers as well as recipients of the feedback. Through engaging in peer/self-feedback, students are affored opportunities to critically comment on peers' writing and hence reflect upon their own writing (Crusan 2010) and to practise their proofreading skills (Ferris 2011). Overall, the findings highlight the active role of language learners in the feedback process: they need to generate feedback from multiple sources such as the teacher, peers, and themselves (Nicol 2010). The teachers' beliefs are also shared by other researchers who argue that triangulating multiple feedback sources contributes to much learning reflection among students (Carroll 2006), and encourages high-level engagement in the feedback processes on the student part (Cheng and Warren 2005).

\section{Conclusion}

Drawing on data from interviews and classroom observations, this study summarizes the three experienced EFL teachers' beliefs about giving feedback on student oral presentations. This study contributes to the knowledge of language teachers' feedback beliefs by expanding the research focus to communicative-oriented oral tasks in EFL classrooms. Although previous research predominantly attempted to identify ESL and EFL teachers' beliefs and knowledge about CF in teaching English oral communication (e.g. Junqueira and Kim 2013; Rahimi and Zhang 2015), the findings of our study extends prior research findings by revealing that the three experienced EFL teachers do not perceive error correction as the primary purpose of their general feedback practices in the communicative task of oral presentation. Instead, the teachers perceived learner acquisition of communicative and presentation competence as the focus of their feedback. The findings of the study also illustrate that the three teachers' feedback beliefs can conceptualized as sociocultural tools of the mind activity mediated by students' L2 proficiency, learning needs as well as affective status, and interacting with the multi-layered context at the instructional, interpersonal and interactional levels. In this sense, although the present investigation was exploratory, future studies could examine how EFL teachers' beliefs can inform their feedback practices in student oral presentation tasks and unveil possible disparity between teacher beliefs and their actual feedback practices in student oral presentations. In view of teacher feedback research in the Chinese context, while most of the previous teacher feedback studies focused on how to conduct error correction so as to enhance linguistic outcomes (e.g. Li and Lin 2007; Yang and Lyster 2010), this study on Chinese EFL teachers' feedback beliefs extend previous research by investigating how teachers conceptualize feedback and why teachers give the feedback to students the way they do. Besides, the teachers in this study attached much importance to such values as confidence, self-regulation, reflection, and the ability to communicate, which seemed to be undervalued in the traditional focus-on-form and teacher-dominated language teaching. Hence, in the wake of recent Chinese EFL teaching reform that introduces Communicative Language Teaching into English classrooms, this study highlights the need to encourage Chinese EFL students to be confident and articulate when undertaking oral language tasks.

Moreover, the present study provides several pedagogical implications for teachers who provide feedback on student oral presentations and for second language teacher training and education programmes. Firstly, the teachers' stated beliefs suggest that it is important to provide formative feedback on successive oral presentation tasks and to 
build in opportunities for students to use and incorporate current feedback to extend their learning and task performance (Brookhart 2008). This provides students with a developmental progression of skills in making oral presentations. Secondly, as the findings demonstrate that giving feedback on oral presentations is intended to help students master course content and develop communicative strategies, it is recommended that teachers should not give excessive consideration to language items when they provide feedback on these communicative-intended language tasks. Thirdly, although teachers can use positive feedback such as praise to establish non-threatening classroom environments, it is suggested that they avoid using low-levels of praise like 'Very good', as this may inhibit rather than encourage advanced language learners' learning (Wong and Waring 2009). Teacher criticism, if framed descriptively and constructively, can be used to support student learning (Hyland and Hyland 2001). Eliciting peer contributions (such as peer feedback) and self-reflection is another recommendation that may be taken from this study. These student-centred practices enrich classroom discourses and lessens the burden of teacher-student interaction. When conducting peer feedback, teachers and students work in partnership and co-construct the feedback. Last but not least, teachers should adapt their feedback to cater to student needs. For example, teachers can give collective feedback when the problems are common to the group or the whole class as one way of extended instruction. Teachers can also communicate with individual students and give feedback specific to individual presentation performances.

The findings of this study also lead us to recognise experienced teachers' role in modelling and mentoring novice and pre-service language teachers, as this study suggests that the case-study teachers' stated beliefs confirm some of the principles of good feedback practices (Nicol and Macfarlane-Dick 2006). Mentor training plays a role in encouraging the sharing of good feedback practices between novices and their mentors. For example, opportunities for mutual classroom observation can be provided to allow mentor-mentee interactions. Experienced teachers can comment on their mentee's performance as a method for prompting reflection on feedback practices.

Abbreviations

CF: Corrective feedback; EFL: English as a foreign language; ESL: English as a second language; L2: Second language; SCT: Sociocultural theory; SLA: Second language acquisition

Availability of data and materials

Data supporting the findings of this qualitative research will not be shared in order to protect the privacy of research participants.

Authors' contributions

The first author collected data and wrote sections of theoretical framework, research finding and discussion. The second author wrote sections of introduction and the study. The third author wrote the section of conclusion. Besides, the first and second authors collaborated in the process of data analysis. All authors read and approved the final manuscript.

Competing interests

The authors declare that they have no competing interests.

Publisher's Note

Springer Nature remains neutral with regard to jurisdictional claims in published maps and institutional affiliations. 


\section{Author details}

${ }^{1}$ Faculty of Education, University of Macau, Room 2042, E33, Av. da Universidade, Taipa, Macau, China. ${ }^{2}$ Faculty of Education, University of Macau, Room 3007, E33, Av. da Universidade, Taipa, Macau, China. ${ }^{3}$ Faculty of Education, University of Macau, Room 4002A, E33, Av. da Universidade, Taipa, Macau, China.

Received: 16 February 2018 Accepted: 14 June 2018

Published online: 20 June 2018

\section{References}

Barcelos, A. M. F. (2003). Researching beliefs about SLA: A critical review. In P. Kalaja \& A. M. F. Barcelos (Eds.), Beliefs about SLA: New research approaches (pp. 7-33). Dordrecht: Kluwer.

Bitchener, J. (2008). Evidence in support of written corrective feedback. Journal of Second Language Writing, 17, 102-118.

Bitchener, J., \& Ferris, D. R. (2012). Written corrective feedback in second language acquisition and writing. New York: Routledge.

Borg, S. (2006). Teacher cognition and language education: Research and Practice London: Continuum.

Brookhart, S. M. (2008). How to give effective feedback to your students. Virginia: Association for Supervision and Curriculum Development.

Brooks, G., \& Wilson, J. (2014). Using oral presentations to improve students' English language skills. Kwansei Gakuin University Humanities Review, 19, 199-212.

Bunch, G. C. (2009). "Going up there": Challenges and opportunities for language minority students during a mainstream classroom speech event. Linguistics and Education, 20(2), 81-108.

Carroll, C. (2006). Enhancing reflective learning through role-plays: The use of an effective sales presentation evaluation form in student role-plays. Marketing Education Review, 16(1), 9-13.

Chaudron, C. (1986). The role of error correction in second language teaching. University of Hawaii Working Papers in English as a Second. Language, 5(2), 43-81.

Cheng, W., \& Warren, M. (2005). Peer assessment of language proficiency. Language Testing, 22(1), 93-121.

Crusan, D. (2010). Assessment in the second language writing classroom. Ann Arbor, MI: The University of Michigan Press.

Dweck, C. S. (2007). The perils and promises of praise. Educational Leadership, 65(2), 34-39.

Ellis, R., Sheen, Y., Murakami, M., \& Takashima, H. (2008). The effects of focused and unfocused written corrective feedback in an English as a foreign language context. System, 36, 353-371.

Fanselow, J. F. (1977). The treatment of error in oral work. Foreign Language Annals, 10(5), 583-593.

Ferris, D. R. (2011). Treatment of error in second language student writing (2nd ed.). Ann Arbor: Ml: The University of Michigan Press.

Forgas, J. P., \& Tehani, G. (2005). Affective influences on language use: Mood effects on performance feedback by experts and novices. Journal of Language and Social Psychology, 24(3), 269-284.

Girard, T., Pinar, M., \& Trapp, P. (2011). An exploratory study of class presentations and peer evaluations: Do students perceive the benefits? Academy of Educational Leadership Journal, 15(1), 77-94.

Hyland, F., \& Hyland, K. (2001). Sugaring the pill: Praise and criticism in written feedback. Journal of Second Language Writing, 10(3), 185-212.

Hyland, K., \& Hyland, F. (2006). Feedback on second language students' writing. Language Teaching, 39(2), 83-101.

Junqueira, L., \& Kim, Y. (2013). Exploring the relationship between training, beliefs, and teachers' corrective feedback practices: A case study of a novice and an experienced ESL teacher. Canadian Modern Language Review, 69(2), 181-206.

King, J. (2002). Preparing EFL learners for oral presentations. Dong Hwa Journal of Humanistic Studies, 4, 401-418.

King, P., Young, M., \& Behnke, R. (2000). Public speaking performance improvement as a function of information processing in immediate and delayed feedback interventions. Communication Education, 49(4), 365-374.

Lee, H. H., Leong, A. P., \& Song, G. (2017). Investigating teacher perceptions of feedback. ELT Journal, 71(1), 60-68.

Lee, I. (2009). Ten mismatches between teachers' beliefs and written feedback practice. ELT Journal, 63(1), 13-22.

Li, H., \& Lin, Q. (2007). The role of revision and teacher feedback in a Chinese college context. Asian EFL Journal, 9(4), 230-239.

Lundstrom, K., \& Baker, W. (2009). To give is better than to receive: The benefits of peer review to the reviewer's own writing. Journal of Second Language Writing, 18, 30-43.

Lyster, R., Saito, K., \& Sato, M. (2013). Oral corrective feedback in second language classrooms. Language Teaching, $46,1), 1-1), 40$

Miles, M. B., \& Huberman, A. M. (1994). Qualitative data analysis: An expanded sourcebook (2nd ed.). Thousand Oaks, CA: Sage.

Min, H. T. (2006). The effects of trained peer review on EFL students' revision types and writing quality. Journal of Second Language Writing, 15, 118-141.

Mori, R. (2002). Teachers' beliefs and corrective feedback. JALT Journal, 24(1), 48-69.

Mori, R. (2011). Teacher cognition in corrective feedback in Japan. System, 39(4), 451-467.

Negueruela-Azarola, E. (2011). Beliefs as conceptualizing activity: A dialectical approach for the second language classroom. System, 39(3), 359-369.

Nicol, D. (2010). From monologue to dialogue: Improving written feedback processes in mass higher education. Assessment \& Evaluation in Higher Education, 35(5), 501-517.

Nicol, D. J., \& Macfarlane-Dick, D. (2006). Formative assessment and self-regulated learning: A model and seven principles of good feedback practice. Studies in Higher Education, 31(2), 199-218.

Pittinger, K., Miller, M., \& Mott, J. (2004). Using real-world standards to enhance students' presentation skills. Business Communication Quarterly, 67(3), 327-336.

Rahimi, M., \& Zhang, L. J. (2015). Exploring non-native English-speaking teachers' cognitions about corrective feedback in teaching English oral communication. System, 55, 111-122. 
Roothooft, H. (2014). The relationship between adult EFL teachers' oral feedback practices and their beliefs. System, $46,65-79$.

Sheen, Y. (2010). Differential effects of oral and written corrective feedback in the ESL classroom. Studies in Second Language Acquisition, 32(2), 203-234.

Skipper, Y., \& Douglas, K. (2012). Is no praise good praise? Effects of positive feedback on children's and university students' responses to subsequent failures. British Journal of Educational Psychology, 82(2), 327-339.

Vygotsky, L. S. (1978). Mind in society: The development of higher psychological processes. Cambridge: Harvard University Press. Wiliam, D. (2001). An overview of the relationship between assessment and the curriculum. In D. Scoot (Ed.), Curriculum and assessment (pp. 165-181). London: Ablex Publishing.

Wong, J., \& Waring, H. Z. (2009). "Very good" as a teacher response. ELT Journal, 63(3), 195-203.

Yang, Y., \& Lyster, R. (2010). Effects of form-focused practice and feedback on Chinese EFL learners' acquisition of regular and irregular past tense forms. Studies in Second Language Acquisition, 32(2), 235-263.

Submit your manuscript to a SpringerOpen ${ }^{\odot}$ journal and benefit from:

- Convenient online submission

- Rigorous peer review

- Open access: articles freely available online

- High visibility within the field

- Retaining the copyright to your article

Submit your next manuscript at $\gg$ springeropen.com 